\title{
Side effects of angiotensin converting enzyme inhibitor (captopril) in newborns and young infants
}

\author{
Monika Herbst Gantenbein ${ }^{1, *}$, Urs Bauersfeld ${ }^{2}$, \\ Oskar Baenziger ${ }^{1}$, Bernhard Frey ${ }^{1}$, Thomas \\ Neuhaus $^{3}$, Felix Sennhauser ${ }^{4}$ and Vera Bernet ${ }^{1}$ \\ ${ }^{1}$ Department of Intensive Care and Neonatology, \\ University Children's Hospital Zurich, Switzerland \\ ${ }^{2}$ Department of Cardiology, University Children's \\ Hospital Zurich, Switzerland \\ ${ }^{3}$ Department of Nephrology, University Children's \\ Hospital Zurich, Switzerland \\ ${ }^{4}$ Department of Pediatrics, University Children's \\ Hospital Zurich, Switzerland
}

\begin{abstract}
Aim: To analyze the side effects of captopril, an angiotensin converting enzyme inhibitor (ACEI) in newborn and young infants.

Methods: Retrospective analysis of side effects in 43 patients with congenital heart disease after cardiac surgery treated with captopril for heart failure during a twoyear period.

Results: Median age of the patients was 26 days (range 6-310 days), median weight $3.5 \mathrm{~kg}$ (range 1.9-7.9 kg). Initial median dose of captopril was $0.17 \mathrm{mg} / \mathrm{kg} /$ day (range $0.05-0.55 \mathrm{mg} / \mathrm{kg} /$ day), slowly increased over 3-33 days to a maximal median dose of $1.86 \mathrm{mg} / \mathrm{kg} / \mathrm{day}$ (range $0.2-2.3 \mathrm{mg} / \mathrm{kg} / \mathrm{day}$ ). All patients were additionally treated with diuretics. Side effects occurred in 17 patients (renal impairment or failure in 6 , low blood pressure in 8 , and oxygen saturation deficit in 3) requiring cessation or interruption in seven patients with renal impairment/failure $(n=4)$, hypotension $(n=1)$ and aortopulmonary shunting with low pulmonary perfusion $(n=2)$. The six children who developed renal impairment or failure did so following a median delay of nine days after reaching the final dose and weighed on average $500 \mathrm{~g}$ less than the other patients $(P=0.046)$. All side effects were fully reversible.
\end{abstract}

Conclusion: Side effects due to captopril were not doserelated in newborns and infants in this study. However, renal side effects occurred more often in smaller infants. Routine monitoring of infants on ACEl should include

\footnotetext{
${ }^{*}$ Corresponding author:

Dr. Monika Herbst Gantenbein

University Children's Hospital Zurich

Steinwiesstrasse 75

$\mathrm{CH}-8032$ Zurich

Switzerland

E-mail: monika.herbst@gmx.ch
}

renal function tests, blood pressure and transcutaneous oxygen saturation measurements.

Keywords: Angiotensin converting enzyme inhibitor; heart failure; hypotension; infant; newborn; renal failure.

\section{Introduction}

In addition to diuretics as standard pharmacotherapy of infants with congenital heart disease, the use of angiotensin converting enzyme inhibitors (ACEls) has become a mainstay in the treatment of children with heart failure over the past 20 years [1,12]. Several studies showed the beneficial effect on morbidity, mortality, and quality of life $[2,3,10,14]$. Captopril has been useful for the treatment of congestive heart failure and hypertension $[2,6,8]$.

ACEls have several mechanisms of action. First, they inhibit the formation of angiotensin II, second, they decrease bradykinin degradation and, third, they inhibit norepinephrine release from sympathetic nerve endings. All these effects produce significant vascular relaxation, reduction of after-load and improvement in cardiac output [3]. Captopril has a bioavailability of $75 \%$ in adults; most of the drug is eliminated through the kidneys as captopril (50\%) and its inactive metabolites (50\%) [2]. Peak serum concentrations can be measured at 1-2 $\mathrm{h}$ after administration, and the average half-life is $3.3 \mathrm{~h}$. ACEls are well tolerated. Occasional side effects include oliguria, acute renal failure, hypotension [2, 11, 12], hyperkalemia, anemia, neurological complications, and dry cough in older children $[3,8]$.

In the human newborn, plasma renin activity, renal renin gene and angiotensin II receptor expression are significantly higher than later in life and they all decrease over the first years of life. Therefore, neonates are more sensitive to the administration of ACEl compared with adults. Both the potency and duration of action of captopril appear to be substantially greater in this age group. Therefore, the initial dose of ACEl in newborns and, particularly in preterm infants, should be considerably lower and the speed of the increase of this drug should be slower than in older individuals $[3,8]$.

The purpose of the study was to evaluate the sideeffects, in particular the renal side-effects of captopril in newborns and young infants with congenital heart disease. 


\section{Patients and methods}

This study is a retrospective analysis of 43 newborns and young infants treated with captopril. All patients were hospitalized in the neonatal ward of the University Children's Hospital Zurich after surgical correction of congenital heart disease. The following data were extracted from the patients' files: gender, age, weight and heart disorder, bypass time, as well as present medication (e.g., diuretics), vital parameters and renal function. In all these patients captopril was commenced after the surgical procedure, based on published beneficial responses to this medication $[8,10,16]$ and based on hospital guidelines. Captopril was generally started with a single oral test dose of 0.05 $\mathrm{mg} / \mathrm{kg}$, and, if well tolerated, regular treatment was started. Dose adjustments were individualized according to the response of each patient, and, if required, doses could be increased in a stepwise manner as frequently as every eight to $24 \mathrm{~h}$. Patients who showed no significant drop in blood pressure 30-60 min after captopril administration could immediately proceed to the next higher dose. Blood pressure was measured indirectly according to Riva-Rocci with an oscillometric method. In newborns (up to 28 days of life), significant drop in blood pressure was defined as a decrease of mean blood pressure to a value of less than mean blood pressure equal to actual 'gestational' age minus ten percent, measured twice in an interval of five minutes in a quiet or sleeping child. In infants of up to three months of age, our mean blood pressure limit is $45 \mathrm{mmHg}$. Measurements were done twice as well and low blood pressure was defined as ten percent below the limit. To prevent hypotension by administration of captopril together with diuretics, diuretics have to be administrated at least $60 \mathrm{~min}$ after captopril.

Renal impairment was defined as creatinine and urea nitrogen levels above the upper limits for the different age groups according to our hospital laboratory guidelines and renal failure was defined when potassium levels were increased as well.

Oxygen desaturation was defined in all patients as transcutaneous oxygen saturation drop for more than five minutes below $90 \%$ in children without a cyanotic cardiac disease. For children with a cyanotic lesion, transcutaneous oxygen saturation had to be over $75-80 \%$, depending on the underlying disease.

A dose reduction was recommended for patients with renal impairment or failure and/or hypotension as well as for patients with a cyanotic heart disease and drop of transcutaneous oxy- gen saturation below $75-80 \%$ after medication for more than 5 $\min$.

For detection and monitoring of the known and previously reported side effects, the following data were collected: blood pressure (before, 30 and 60 min after captopril administration), blood tests for renal function every 3-6 days, including creatinine, potassium and urea nitrogen and fluid intake.

Differences between groups were analyzed using the MannWhitney $U$-test. A P-value $<0.05$ was considered statistically significant.

\section{Results}

The median age of the patients on starting captopril was 26 days (range 6-310 days) and the median weight $3.5 \mathrm{~kg}$ (range 1.9-7.9 kg). Twenty-three children were newborns (5 of them born prematurely), 20 patients were older than four weeks. The male-to-female ratio was nearly $1: 1$. All patients were treated either after a corrective or a palliative operation. Diagnoses of the patients are summarized in Table 1. For close observation of any possible side effects, all patients were hospitalized at the time of captopril introduction.

Captopril was started with an initial dose of $0.05-0.55 \mathrm{mg} / \mathrm{kg} /$ day (median $0.17 \mathrm{mg} / \mathrm{kg} /$ day) in three divided doses, thereafter and if tolerated, slow increase in median increments of $0.34 \mathrm{mg} / \mathrm{kg} /$ day was started, aiming for a target dose of $1.5 \mathrm{mg} / \mathrm{kg} /$ day (median final dose $1.86 \mathrm{mg} / \mathrm{kg} /$ day, range $0.2-2.3 \mathrm{mg} / \mathrm{kg} /$ day). The median duration to reach steady state dose was nine days (range 3-33 days). All patients were additionally treated with diuretics, on the day of captopril introduction with furosemide at a median dose of $1.45 \mathrm{mg} / \mathrm{kg} / \mathrm{day}$ (range $0.37-12 \mathrm{mg} / \mathrm{kg} /$ day) and spironolactone $(6.25 \mathrm{mg}$ once daily). Furosemide was replaced as quickly as possible by hydrochlorothiazide on a median dose of $2.31 \mathrm{mg} / \mathrm{kg} /$ day (range 1.01-8.62 mg/kg/day) with continuing spironlactone therapy as part of heart failure therapy if serum potassium levels were within the normal range. In 26 children the treatment with captopril was well tolerated and the therapy was clinically effective. In

Table 1 Main diagnoses of the 43 patients.

\begin{tabular}{lccc}
\hline Diagnosis & All patients & Renal impairment & $\begin{array}{c}\text { Hypotension } \\
\text { deficit }\end{array}$ \\
\hline Transposition of the great arteries & 12 & 1 & 0 \\
Hypoplastic left heart & 4 & 1 & 2 \\
DORV (double outlet right ventricle) & 4 & 0 & 1 \\
VSD (ventricular septal defect) & 3 & 0 & 1 \\
AIST (aortic isthmus stenosis) & 3 & 1 & 1 \\
Aortic stenosis & 3 & 0 & 0 \\
Pulmonary atresia & 3 & 0 & 2 \\
AV-canal (atrio-ventricular canal) & 3 & 1 & 0 \\
Interrupted aortic arch, fallot tetralogy, & 2 each & Fallot tetralogy & 0 \\
truncus arteriosus communis, tricuspid & & interrupted & 0 \\
valve atresia & & aortic arch & 0 \\
\end{tabular}




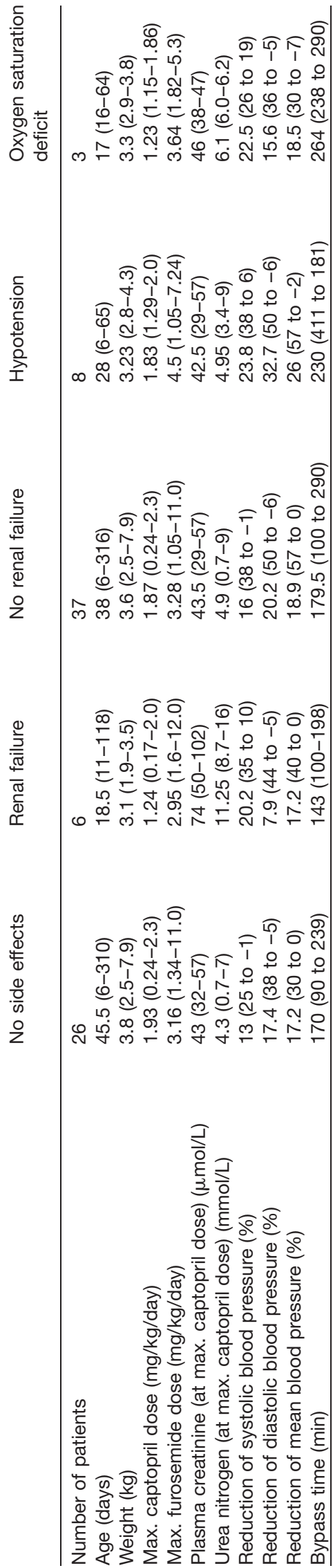

17 patients we found the following side effects: renal impairment/failure, hypotension, and arterial oxygen saturation deficit (Table 2).

\section{Renal impairment/failure}

Renal impairment occurred in five and renal failure in one patient (total $14 \%$ ) with increase of median blood urea nitrogen up to $11.25 \mathrm{mmol} / \mathrm{L}$ (range $8.7-16 \mathrm{mmol} / \mathrm{L}$ ) and creatinine up to $74 \mu \mathrm{mol} / \mathrm{L}$ (range 50-102 $\mu \mathrm{mol} / \mathrm{L}$ ) (Table 2). The patient with renal failure was born with hypoplastic left heart syndrome and required Norwood I procedure. He developed renal failure with high urea and creatinine and maximal potassium of $6.2 \mathrm{mmol} / \mathrm{L}$. In three patients captopril had to be ceased permanently, including the patient with renal failure. In one child the treatment had to be interrupted and in another patient captopril was temporarily lowered to a dose of 0.54 $\mathrm{mg} / \mathrm{kg} /$ day until renal function normalized. Afterwards the medication was re-increased without renal problems. The sixth patient had raised urea nitrogen at full dose, which normalized spontaneously within three days. In the other five children urea nitrogen and creatinine crossed the upper normal limits following a median delay of nine days after reaching the final dose.

We looked at the bypass time in the different groups as a factor for renal problems and could not show a significant difference between the renal impairment/failure group and the patients without side effects $(P=0.26)$.

The median age of these six children (18.5 days, range 11-118 days) was not significantly different than the median age of the other children without renal problems $(P=0.66)$, but their weight $(3.1 \mathrm{~kg}$, range 1.9-3.5 kg) was significantly lower $(P=0.046)$. The maximal median captopril dose of the infants who developed renal impairment or failure was $1.24 \mathrm{mg} / \mathrm{kg} /$ day $(0.17-2 \mathrm{mg} / \mathrm{kg} /$ day) compared to $1.67(0.24-2.3 \mathrm{mg} / \mathrm{kg} /$ day $)$ in patients without renal dysfunction $(P=0.18)$.

The furosemide dose at the beginning of captopril treatment was $2.95 \mathrm{mg} / \mathrm{kg} /$ day (range 1.6-12 mg/kg/day) and $3.28 \mathrm{mg} / \mathrm{kg} /$ day (range $1-11 \mathrm{mg} / \mathrm{kg} /$ day) in the renal impairment/failure group- and non-renal group, respectively $(P=0.67)$. Renal impairment/failure was reversible in all patients.

Potassium levels have not been measured regularly for all patients, therefore no statistical analysis was done.

\section{Hypotension}

Eight children (19\%) repeatedly showed hypotensive episodes and treatment was adjusted either by dose reduction or by slower increase of the dose. Diagnoses are listed in Table 1. The children with hypotensive episodes had a median reduction of the systolic blood pressure of $23.8 \%$ after administration of captopril (compared to $13 \%$ in the group of patients without side effects). The median reduction of the diastolic blood pressure was 
$32.7 \%$ (vs. $17.4 \%$ ) and $26 \%$ (57 to -2 ) for the mean blood pressure. Compared to the patients without side effects, the time on bypass was significantly longer $(P=0.002)$.

The median age of these eight patients was 28 days (range 6-65 days) and their median weight was $3.23 \mathrm{~kg}$ (range 2.8-4.3 kg) (Table 2). The maximal captopril dose was $1.83 \mathrm{mg} / \mathrm{kg} /$ day. These patients received the highest furosemide dose $(4.5 \mathrm{mg} / \mathrm{kg} /$ day $)$ when captopril was started. The patients with low blood pressure had a tendency to a longer time period until reaching the maximal dose and to require more dose adjustments compared to the rest of the patients (16 days, 7 steps vs. 10 days, 6 steps, respectively).

\section{Oxygen saturation deficit}

Three infants had transcutaneous oxygen saturation drops on captopril. All of them had single ventricle pathology. In two patients treatment was interrupted and in one of them treatment was even stopped because of bad general state of health. One child normalized his transcutaneous oxygen saturation when the daily dose was reduced. The median age and weight of these three patients were 17 days and $3.3 \mathrm{~kg}$ (Table 2). The median maximal captopril dose was $1.23 \mathrm{mg} / \mathrm{kg} /$ day. The individual blood pressures in these three patients were $70 / 40$ with a mean of $50,74 / 40$ with a mean of 47 and 56/28 with a mean of 38 . Reduction of blood pressure is shown in Table 2.

\section{Discussion}

In the present study we evaluated retrospectively the side effects of captopril in newborn and young infants with congenital heart disease. The most common side effect was hypotension $(n=8)$, which required adaptation of drug dose. A possible explanation for the decreased blood pressure may be the combination of captopril with furosemide, although they were not given at the same time.

The second most common side effect was reversible renal impairment or failure. The weight of patients with renal impairment/failure was significantly lower compared to the weight of infants without renal side effects. We could not find a correlation between renal side effects and diuretic therapy. In fact, the infants with renal problems were on lower doses of diuretics compared to the infants without renal side effects.

Leversha et al. [5] described an association between young age, low weight, left-to-right shunt and renal failure in children on captopril. However, renal impairment was not dose related. These authors found side effects in $28 \%$ of 63 patients, who had been treated with a mean maximal dose of ACEl of $0.3 \mathrm{mg} / \mathrm{kg} /$ day (range 0.04-0.94 mg/kg/day): hypotension occurred in nine children and renal failure was observed in eight infants. Renal failure developed within five days of starting treatment and all of the renal failure patients were less than four months of age, had left-to-right shunts and received digoxin and diuretics. The authors recommended special care to the small infants and especially suggested that potassium sparing diuretics should be discontinued when starting ACEI. Similarly, Shaddy et al. [11] presented a group of 10 infants, of whom the smallest and youngest child developed acute renal dysfunction after a single dose of $0.5 \mathrm{mg} / \mathrm{kg}$ captopril. Hypotension was found in seven of the ten patients.

Focusing on operative bypass time as an important factor for renal dysfunction we could not find a difference between the renal dysfunction group and the patients without any side effect. Compared to that, bypass time was significantly longer in the patients with hypotension. We could not find a physiological explanation for this finding.

The three patients with oxygen saturation deficit had been diagnosed with a single ventricle. The drop in arterial oxygen saturation may be explained by decreasing peripheral arterial resistance and consecutive mismatch of the lung and body perfusion. Because the number of patients in this group is very small this speculation needs verification in a prospective study.

Even though our patients had an adequate dose of captopril of $<1.9 \mathrm{mg} / \mathrm{kg} / \mathrm{day}, 39.5 \%$ of them showed side effects. In our study renal side effects occurred with an average delay of nine days after achieving full dose. In some other studies side effects usually appeared shortly after beginning treatment or when patients reached the full dose $[5,10,12]$. However, there is also evidence for a delayed and unpredictable onset of side effects unrelated to the dose [4, 6]. Tack et al. [17] retrospectively analyzed nine young infants after a starting dose of $0.3 \mathrm{mg} / \mathrm{kg}$ captopril. The systolic blood pressure decreased significantly in all infants. After halving the dosage, hypotension still occurred between 1-54 days after starting treatment. During therapy four infants had an increase in urea and creatinine values in association with oliguria. Therefore, they recommend a starting dose of $0.1-0.2 \mathrm{mg} / \mathrm{kg} / \mathrm{day}$ and a maintenance dose of $0.6 \mathrm{mg} / \mathrm{kg} /$ day in premature infants. It is important for the neonatologist and pediatrician to be aware of the delayed and unpredictable side effects.

Early clinical trials used high doses of captopril of up to $3.5 \mathrm{mg} / \mathrm{kg} /$ day in infants and of up to $6 \mathrm{mg} / \mathrm{kg} / \mathrm{day}$ in older children which caused dose-related adverse effects [4, 6, 10]. Calligaro and Burman [2] described a doserelationship with renal dysfunction in neonates on diuretics and ACEI. In our study hypotension was related to high doses of captopril, but renal side effects occurred with even lower doses. Conservative initial doses are recommended $(0.05-0.1 \mathrm{mg} / \mathrm{kg} /$ day), especially in neonates, who are highly susceptible to adverse effects 
associated with ACEls $[1,9,13,14]$. Starting with low doses may decrease the incidence of adverse reactions and may improve the patients' tolerance of this treatment. It is important to select patients carefully, identify their risk factors (risk profile: congestive heart failure, high doses of diuretics, elevated plasma renin activity, volume depletion, single ventricle) and use more rational and patient adapted dosing schemes. Shaw et al. [12] surveyed 20 young infants on captopril with an initial dose of $0.25-0.5 \mathrm{mg} / \mathrm{kg} /$ day and a maximal daily dose of $0.88-2.5 \mathrm{mg} / \mathrm{kg}$ (mean $1.3 \mathrm{mg} / \mathrm{kg} /$ day), all being treated with furosemide (2.2-8.5 mg/kg/day) and spironolactone $(1.5-10 \mathrm{mg} / \mathrm{kg} /$ day). Side effects had been seen in four patients - two with mild hypotension and two with renal impairment, all of them recovered on a lower dose. The authors concluded that patients benefited from a low dose, at most $1.5 \mathrm{mg} / \mathrm{kg} /$ day. This has been supported by Scammell et al. [10] in a similar study. O'Dea et al. [7] used low initial doses $(0.13 \mathrm{mg} / \mathrm{kg} /$ day $)$ and increased to a maximum of $0.85 \mathrm{mg} / \mathrm{kg} /$ day to treat neonatal hypertension. They found a positive antihypertensive response to captopril and this regimen was not associated with hypotension, changes in serum creatinine or reduction in urine output. They recommended captopril as an effective antihypertensive drug in neonates and suggested a low initiating dose with the lowest maintenance dose possible that still elicited an effective clinical response.

Beside the limitation that this is a retrospective study, it is very difficult to attribute a side-effect of a drug, directed to such a clinical setting. Side effects of drugs are sometimes influenced by unobvious or not measurable factors in the cardio-vascular status of a patient, or the result of individual pharmacokinetics of a patient on different drugs.

A review of the current literature about captopril did not allow us to draw a conclusive strategy for drug administration and maximal dosage. From our experience, we suggest a dose range between 1 and 1.5 $\mathrm{mg} / \mathrm{kg} /$ day in newborns and infants $[1,7,12]$. All published studies showed that cardiac function was not improved at higher doses, but the risk of serious side effects was generally increased, especially renal dysfuncion and hypotension $[1,15,17]$. Therefore, a dose of $1.5 \mathrm{mg} / \mathrm{kg} /$ day should not be exceeded in this age-group and careful monitoring is mandatory, especially in the younger and smaller infants $[5,11]$.

\section{Conclusion}

Renal side effects due to captopril were not dose related in newborns and infants in our study. However, renal side effects occurred more often in the smaller infants. Other common side effects are hypotension and arterial oxygen saturation deficit. Therefore, routine monitoring in infants treated with captopril should include renal function tests, blood pressure, and transcutaneous arterial oxygen saturation measurements. Long-term studies in a larger population are required to confirm our findings and to elicit the benefits of captopril.

\section{References}

[1] Buchhorn R, Ross RD, Hulpke-Wette M, Bartmus D, Wessel A, Schulz R, et al. Effectiveness of low dose captopril versus propranolol therapy in infants with severe congestive failure due to left-to-right shunts. Int J Cardiol. 2000; 76:227-33.

[2] Calligaro IL, Burman CA. Pharmacologic considerations in the neonate with congenital heart disease. Clin Perinatol. 2001;28:209-22.

[3] Clark BJ 3rd. Treatment of heart failure in infants and children. Heart Dis. 2000;2:354-61.

[4] Hanna JD, Chan JC, Gill JR Jr. Hypertension and the kidney. J Pediatr. 1991;118:327-40.

[5] Leversha AM, Wilson NJ, Clarkson PM, Calder AL, Ramage MC, Neutze JM. Efficacy and dosage of enalapril in congenital and acquired heart disease. Arch Dis Child. 1994;70:35-9.

[6] Mirkin BL, Newman TJ. Efficacy and safety of captopril in the treatment of severe childhood hypertension: report of the International Collaborative Study Group. Pediatrics. 1985;75:1091-100.

[7] O'Dea RF, Mirkin BL, Alward CT, Sinaiko AR. Treatment of neonatal hypertension with captopril. J Pediatr. 1988; 113:403-6.

[8] Parish RC, Miller LJ. Adverse effects of angiotensin converting enzyme (ACE) inhibitors. An update. Drug Saf. 1992;7:14-31.

[9] Reznik V, Griswold W, Mendoza S. Dangers of captopril therapy in newborns. Pediatrics. 1989;83:1076.

[10] Scammell AM, Arnold R, Wilkinson JL. Captopril in treatment of infant heart failure: a preliminary report. Int J Cardiol. 1987;16:295-301.

[11] Shaddy RE, Teitel DF, Brett C. Short-term hemodynamic effects of captopril in infants with congestive heart failure. Am J Dis Child. 1988;142:100-5.

[12] Shaw NJ, Wilson N, Dickinson DF. Captopril in heart failure secondary to a left to right shunt. Arch Dis Child. 1988; 63:360-3.

[13] Sinaiko AR. Treatment of hypertension in children. Pediatr Nephrol. 1994;8:603-9.

[14] Sinaiko AR, Mirkin BL, Hendrick DA, Green TP, O'Dea RF. Antihypertensive effect and elimination kinetics of captopril in hypertensive children with renal disease. J Pediatr. 1983;103:799-805.

[15] Sinaiko AR, Kashtan CE, Mirkin BL. Antihypertensive drug therapy with captopril in children and adolescents. Clin Exp Hypertens A. 1986;8:829-39.

[16] Stern H, Weil J, Genz T, Vogt W, Buhlmeyer K. Captopril in children with dilated cardiomyopathy: acute and longterm effects in a prospective study of hemodynamic and hormonal effects. Pediatr Cardiol. 1990;11:22-8.

[17] Tack ED, Perlman JM. Renal failure in sick hypertensive premature infants receiving captopril therapy. J Pediatr. 1988;112:805-10.

Received July 18, 2007. Revised April 3, 2008. Accepted April 17, 2008. Previously published online June 12, 2008. 